\title{
$\mathrm{PH} 9 \mathbf{1}_{\text {panorama }}$
}

\section{El IAPH crea nuevos productos didácticos y divulgativos}

El estudio y la conservación del patrimonio cultural son labores multidisciplinares en las que participan profesionales de muy distintos ámbitos, desde la restauración y la antropología, hasta la química, la biología, o la fotografía y la historia del arte. El Instituto Andaluz del Patrimonio Histórico a través de la Unidad de Cultura Científica (UCC+i), ha creado nuevos productos divulgativos para escolares. Pretenden apoyar la labor docente en la difícil tarea de mostrar el conjunto de disciplinas que intervienen en el proceso de preservación patrimonial, al tiempo que desean fomentar nuevas vocaciones científicas y sensibiblizar a la comunidad educativa sobre la necesidad de conservar su legado.

Instituto Andaluz del Patrimonio Histórico, Unidad de Cultura Científica (UCC+i)

URL de la contribución <www.iaph.es/revistaph/index.php/revistaph/article/view/3912>

A los ojos de buena parte de la sociedad y de la comunidad educativa son los profesionales del ámbito de las ciencias solciales (principalmente dedicados a la restauración, conservación y estudios históricos de la obra de arte) quienes casi exclusivamente asumen el encargo de preservar el patrimonio cultural. Sin embargo esta labor, lejos de estar restringida a unas cuantas disciplinas, requiere la participación de equipos multidisciplinares en los que se incluyen también, siempre dependiendo de la naturaleza del bien atendido, materias que hasta el momento se consideraban ajenas al desarrollo de estos cuidados (entre otras la antropología, química, geología, biología, fotografía, etc.).

Con el fin de dar a conocer a la sociedad en general, y al sector educativo en particular, la importante labor científica multidisciplinar que se realiza para el estudio y conservación de nuestro patrimonio cultural, el IAPH, a través de $\mathrm{UCC}+\mathrm{i}$, ha desarrollado nuevos productos didácticos y divulgativos fruto dos proyectos:

> Elaboración de materiales didácticos: Las ciencias del patrimonio cultural, y

$>$ Apoyo al programa de la UCC+i del IAPH.

Ambos aprobados y cofinanciados por el Ministerio de Economía, Industria y Competitividad en el marco de la Convocatoria de ayudas para el fomento de la cultura científica la tecnología y la innovación (2015) de la Fundación Española para la Ciencia y la Tecnología (FECYT).

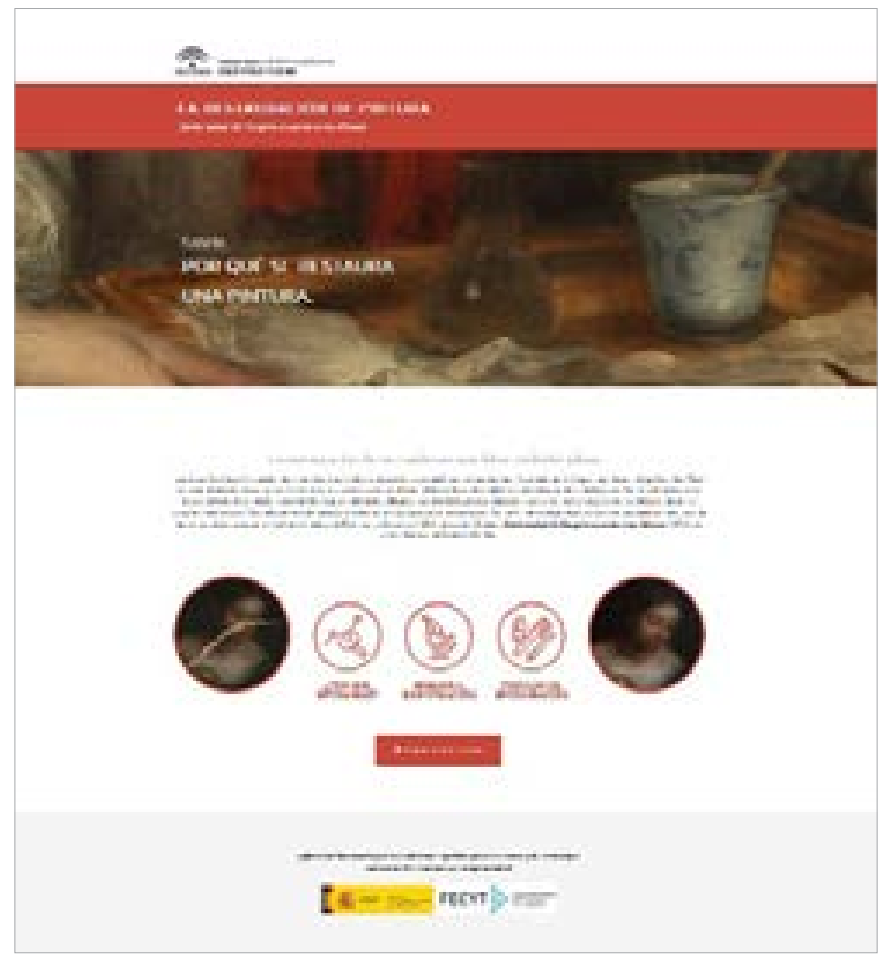

Los recursos didácticos elaborados son de diferente naturaleza, teniendo como destinatarios alumnos de distintos niveles educativos.

Todos los productos son de uso libre y gratuito pudiendo consultarse en línea a través de la sección Zona didáctica de la web del IAPH (http://www.iaph.es/web/canales/ didactica/). A continuación se describen las temáticas. abordadas. 
> Las ciencias del patrimonio: una labor multidisciplinar. Presenta la labor que profesionales de diferentes disciplinas realizan para mejorar el conocimiento histórico y del estado de conservación de los bienes culturales.

Nivel educativo: $3 .^{\circ}$ y $4 .^{\circ}$ de ESO y Bachillerato.

Productos: web y audiovisuales, juego didáctico.

$>$ Restauración de pintura. Explica el proceso de restauración de un cuadro y los diferentes tipos de estudios y técnicas que se aplican.

Nivel educativo: $3 .^{\circ}$ y $4 .{ }^{\circ}$ de ESO y Bachillerato.

Productos: web, guía, juego, exposición y talleres didácticos.

$>$ Restauración de escultura. Explica el proceso de restauración de una escultura y los diferentes tipos de estudios y técnicas que se utilizan para para ello.

Nivel educativo: $5 .^{\circ}$ y $6 .^{\circ}$ de Primaria y $1 .^{\circ}$ y $2 .^{\circ}$ de ESO. Productos: web, guía, exposición, audiovisual, juego y talleres didácticos.

$>$ Patrimonio en piedra. Muestra las causas de alteración de la piedra en monumentos y esculturas, así como lostratamientos aplicados para su conservación.

Nivel educativo: $3 .^{\circ}$ y $4 .{ }^{\circ}$ de ESO y Bachillerato.

Productos: web, guía, exposición y talleres didácticos.

$>$ Patrimonio mueble urbano. Presenta la forma de documentar y analizar los elementos del patrimonio mueble urbano.

Nivel educativo: $3 .^{\circ}$ y $4 .^{\circ}$ de ESO y Bachillerato.

Productos: web, guía didáctica, concurso escolar.
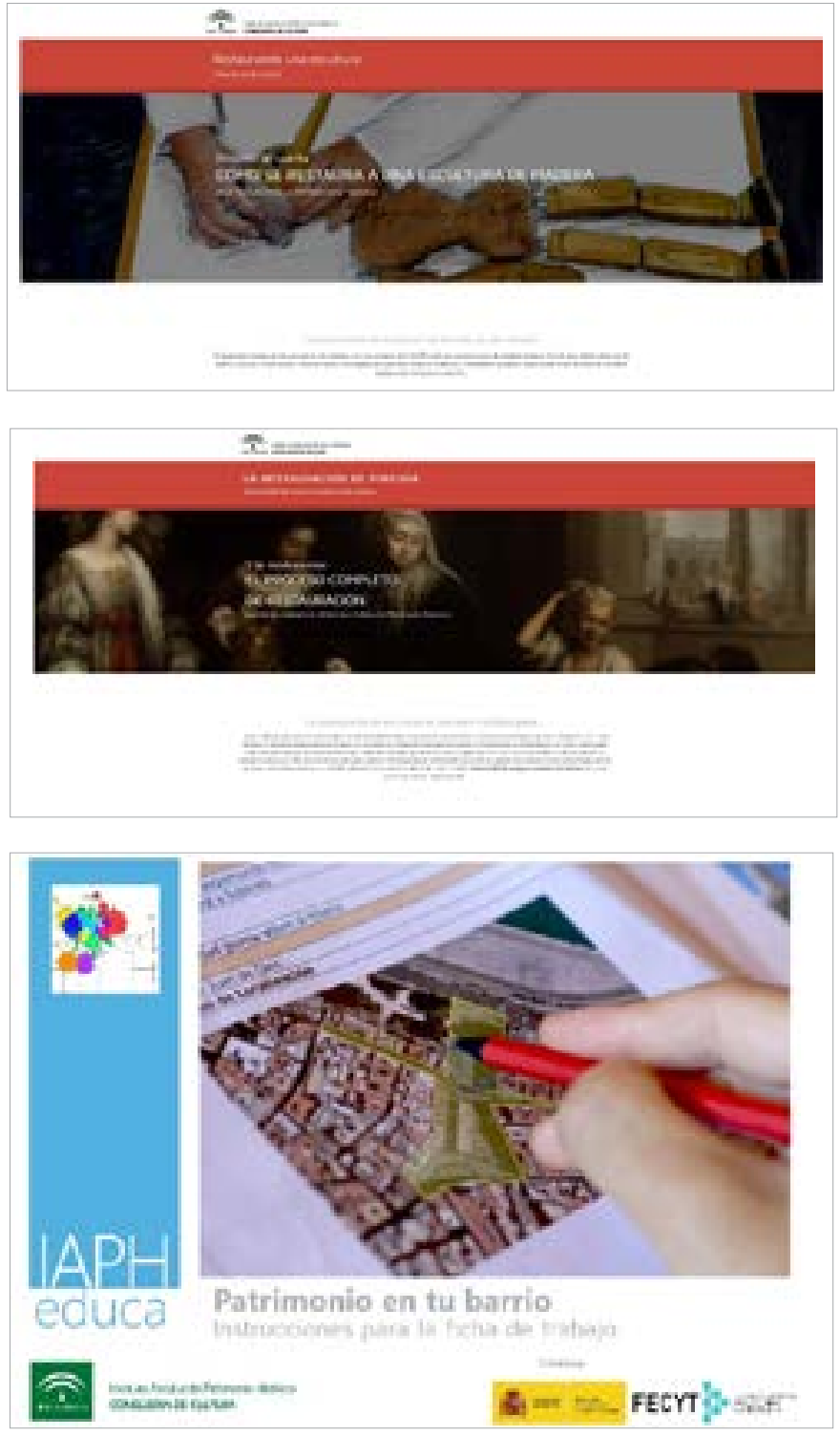